\title{
Factors Associated with Illegal Fishing Practices in Three Perennial Reservoirs in Sri Lanka
}

\author{
E.S. Wickremasinghe ${ }^{1 *}$, C.M.B. Dematawewa ${ }^{2}$, and U. Edirisinghe \\ Postgraduate Institute of Agriculture \\ University of Peradeniya \\ Sri Lanka
}

\begin{abstract}
A study was conducted to investigate the socioeconomic and management factors affecting illegal fishing practices that cause an irreparable damage to the fish resources in Victoria, Sorabora and Ulhitiya reservoirs. A total of 368 fishers were surveyed representing all landing sites of the three reservoirs on their socioeconomic status and fishing practices. Illegal fishing gear confiscated and incidences of illegal fishing were quantified using records of relevant government authorities. Chi-square analysis was conducted to determine the association between involvement in illegal fishing and each of the socioeconomic and management factors. Linear logistic model analysis was performed to determine the odds and relative risk of factors affecting illegal fishing. Characteristics of fishers such as frequent consumption of alcohol, non-willingness to organize into a fisheries society and noncompliance with fisheries regulations were significantly associated with the engagement in illegal fishing in all the three reservoirs $(p<0.05)$. In addition, in Victoria reservoir, those fishers holding positions in the Fisheries Society and voluntarily participating in official raids were found to be significantly less prone to engage in illegal fishing activities ( $p$ <0.05). In Ulhitiya, factors such as obtaining license and registration of boats and gear and fishing (full/part time) were significantly associated with illegal fishing $(p<0.05)$. Tendency to be involved in illegal fishing was lesser among those who achieved better education (primary or higher) in Sorabora and Ulhitiya ( $p<0.05)$. Training programs were effective in reducing tendency for illegal fishing only in Sorabora fishing community $(p<0.05)$. This study confirmed that a reservoir-specific co-management strategy is required as an effective management procedure to minimize illegal fishing practices in these reservoirs.
\end{abstract}

Keywords: Reservoirs, co-management, fisheries organization, illegal fishing, socioeconomics

\section{INTRODUCTION}

Sri Lanka has extensive freshwater resources for fisheries with over 10,000 reservoirs. Fisheries industry contributes to $2 \%$ of total GDP providing about 2.4 million of direct and indirect employment opportunities, while bringing in foreign exchange earnings of Rs. 21,015 million and supplying much needed animal protein especially to the rural communities (Anonymous, 2013). It has been estimated that freshwaters of the country have the potential to produce $125,000 \mathrm{Mg}$ of fish annually though the current production level,

National Aquaculture Development Authority, Sri Lanka

Department of Animal Science, Faculty of Agriculture, University of Peradeniya, Sri Lanka

* Corresponding author: shehanwickrema@yahoo.com 
which remains at 90,000 Mg (Anonymous, 2016). Full potential of the resource has not been realized due to lack of effective strategies for management of fisheries (De Silva, 1988; Kulathilake et al., 2010). Illegal fishing and non-compliance of regulations are commonly considered as serious problems to fisheries (Etiegni et al., 2011). Discontinuation of state patronage for inland fisheries in 1990 has led to a subsequent rise in illegal fishing in the reservoirs which clearly demonstrates the necessity of a state-sponsored management system for Sri Lankan reservoirs (Amarasinghe and De Silva, 1999). Currently, inland fisheries management regulations are imposed under Fisheries and Aquatic Resources Act No. 2 of 1996 to mitigate illegal fishing activities. In Sri Lanka, inland fishery acts as a cheaper source of animal protein and a primary source of income for fishing community in rural areas, however the main means of over exploitation are illegal fishing practices (De Silva, 1988).

Effectiveness of aquatic resource management practices could vary depending on the reservoir and the respective fishing community. Compared to the seasonal and minor perennial reservoirs, major and medium perennial reservoirs are ideal for studying the management issues as they involve a relatively large fishing community and other stakeholders, and also the development of those resources has comparatively high economic and social impact (Wickremasinghe et al., 2009). Therefore, the objectives of this study were to quantify the illegal fishing practices occurring in three major perennial reservoirs in Sri Lanka, namely Victoria, Sorabora and Ulhitiya, and to identify and compare the socioeconomic and management factors affecting illegal fishing practices in the three reservoirs along with appropriate remedial measures.

\section{METHODOLOGY}

\section{Locations of the study}

The study was carried out using the fishing communities of three major perennial reservoirs namely Victoria, Sorabora and Ulhitiya reservoirs. Victoria reservoir is mainly fed by Mahaweli ganga and Hulu ganga, and distributed over four Divisional Secretariats of Kandy District covering 2380 ha of surface area at full supply level (FSL). It has a characteristically deeper gradient and a large volume compared to the other two reservoirs. Though the Victoria reservoir was primarily built for irrigation and hydroelectric power generation, it has become an invaluable resource for the surrounding fishing community with 10 landing sites. Ulhitiya is the largest reservoir (1,261 ha at FSL) in the northern region of Badulla District in Uva Province with 2 landing sites and spread over one Divisional Secretariat. This reservoir is maintained by Mahaweli Development Authority and fed by Mahaweli south cannel and Ulhitiya Oya. As a medium scale tank (461 ha at FSL), Sorabora spreads over two Divisional Secretariats with two landing sites. With a well-known historical background, it is located in the northern region of Badulla District which is a relatively dry area. Sorabora is mainly fed by Diyabana-oya and Mahaweli water from Minipe south channel under the management of Irrigation Department.

\section{Data collection and analysis}

A survey was carried out using a pre-tested questionnaire among fishermen in the fisheries societies of the three reservoirs, to gather the required socio-economic information of fishing communities during the period of 2014 to 2015. All full-time fishermen of Victoria $(n=132)$, Sorabora $(n=125)$ and Ulhitiya $(n=111)$ were included in the survey. The extent 
of illegal fishing activities by each fisherman was quantified using the information collected on raids conducted by the responsible government agencies and fisheries societies of the reservoirs. Issues related to respective fishery and fisheries societies were recorded by participating in monthly meetings during the two years. The classificatory variables were coded accordingly before calculating relative frequency of each category. Chi-square analysis was performed using PROC FREQ option in $S A S{ }^{\circledR}$ software package to determine the association between involvement in illegal fishing and each of the socioeconomic and management factors in the three reservoirs $(P=0.05)$. The socioeconomic factors identified as likely to be having a relationship with illegal fishing were considered in the survey, and those included education level $(1=$ none, $2=$ primary, $3=$ secondary and $4=$ higher $)$, level of engagement in fishing ( 1 = full-time, 2 = part-time), family size, frequency of alcohol consumption $(1=$ teetotaler, $2=$ rarely taken, $3=$ occasional, $4=$ daily), smoking (yes $/$ no), and the habit of saving from income earned $(0=0 \%, 1=1-5 \%, 2=6-10 \%$ and $3=>10 \%$ of income). The management factors included holding positions in fisheries society (held, holding, never), participation at management meetings (yes/no), loans obtained from the organization (yes/no), licesing and registration of boats and fishing gear (yes/no), trainings received (yes/no), net and boat subsidies received (yes/no), voluntary participation in state conducted raids (yes/no), willingness to comply with fisheries regulations (yes/no), willingness to organize into fisheries societies (yes/no), etc. Subsequently, linear logistic model analysis was performed (considering three risk factors at a time) using the following model to determine the odds and relative risk of involving in illegal fishing by the above risk factors:

$\ln \left(\frac{P_{i j k}}{1-P_{i j k}}\right)=\alpha+\beta_{i}+\gamma_{j}+\delta_{k}+(\beta \gamma)_{i j}+(\beta \delta)_{i k}+(\gamma \delta)_{j k}$

where, $\alpha=$ intercept; $\beta_{i}, \gamma_{j}$ and $\delta_{k}$ are $i^{\text {th }}, j^{\text {th }}$ and $k^{\text {th }}$ levels (respectively) of a set of three of the above risk factors (main factors and their 2-way interactions). $P_{i j k}$ is the proportion of fishers involved in illegal fishing at the $i^{\text {th }}, j^{\text {th }}$ and $k^{\text {th }}$ levels of the three risk factors considered, respectively. Hence, 1- $P_{i j k}$ is the proportion not involved in illegal fishing, whereas $\left(P_{i j k} / 1-P_{i j k}\right)$ is the odds of involving in the illegal activity. Comparison (i.e. ratio) of the odds between two levels of a risk factor provides the respective odds ratio, which indicates the relative risk of involving in the illegal activity by one level over the other of a risk factor. Due to the large number of risk factors involved with limited number of fishers, 3 factors were considered at a time and analysis was repeated exhaustively. Parameter estimates and confidence intervals for respective odds ratios were obtained from maximum likelihood method using CATMOD procedure in SAS software.

\section{RESULTS AND DISCUSSION}

\section{Illegal fishing practices}

Fisheries Extension Officers of National Aquaculture Development Authority of Sri Lanka (NAQDA), Officers of Police Department and Wildlife Department individually and jointly had been conducting raids with the help of fisheries societies in the three reservoirs during the study period (2014-2015). Total number of incidences of illegal fishing activities was recorded as 39 times by 18 fishers with a maximum of 5 attempts per fisher in Victoria, 45 times by 23 fishers with a maximum of 4 attempts per fisher in Sorabora and 31 incidences by 24 fishers with a maximum of 2 per fisher in Ulhitiya. Authorized as well as unauthorized 
fishers tend to involve in illegal fishing activities if frequent raids are not being conducted (Sumaila et al., 2006).

Use of monofilament nets was found to be the most common unlawful fishing activity occurs in all three reservoirs (Table 1). Due to high volume of fish catch, most fishers opted to use this type of nets as amount of fish that can be caught by legally allowed nets was lesser than those from monofilament nets (Wickemasinghe et al., 2009). Though monofilament nets are banned, scientific evidence on its true effect on fish resources are scanty. Thus, a critical evaluation of the rationale behind the banning is needed. Fishers were also using nets with smaller mesh size $(<85 \mathrm{~mm})$ in all three reservoirs (Table 1). Juvenile fish are often caught by the small meshed nets causing an irreparable damage to the fish resource. Beach seines cause the most adverse impact to the fishery in reservoirs. It sweeps the bottom of the reservoir disturbing the habitat while all the stages of fish are caught into the cod end. Unfortunately, Sorabora reservoir has a favorable situation for the use of beach-seine nets as the bottom of the reservoir was shallow and has only a few natural obstacles. Almost all cast nets used had been less than $85 \mathrm{~mm}$ of mesh size in all the reservoirs. However, the impact of cast-net was not adverse. In addition to those, water beating to increase catch, fishing without an operation license, use of boats without registration and fishing on non-permitted times were the other improper fishing practices recorded in the three reservoirs.

Table 1. Number of incidences of use of illegal fishing gear in the three reservoirs during the period of 2014-2015

\begin{tabular}{|c|c|c|c|c|c|c|c|c|c|c|c|}
\hline \multirow{3}{*}{ Tank } & \multicolumn{10}{|c|}{ Type of illegal fishing gear/practice } & \multirow{3}{*}{ Total } \\
\hline & \multicolumn{2}{|c|}{$\begin{array}{c}\text { Monofilament } \\
\text { nets }\end{array}$} & \multicolumn{2}{|c|}{$\begin{array}{l}<85 \mathrm{~mm} \\
\text { mesh size }\end{array}$} & \multicolumn{2}{|c|}{ Beach seines } & \multicolumn{2}{|c|}{ Cast nets } & \multicolumn{2}{|c|}{ Others } & \\
\hline & 2014 & 2015 & 2014 & 2015 & 2014 & 2015 & 2014 & 2015 & 2014 & 2015 & \\
\hline Victoria & 41 & 26 & 13 & 10 & 00 & 00 & 11 & 06 & 07 & 04 & 118 \\
\hline Sorabora & 20 & 12 & 12 & 08 & 02 & 00 & 08 & 07 & 07 & 11 & 87 \\
\hline Ulhitiya & 18 & 13 & 14 & 07 & 00 & 00 & 09 & 06 & 04 & 05 & 76 \\
\hline Total & 79 & 51 & 39 & 25 & 02 & 00 & 28 & 19 & 18 & 20 & 281 \\
\hline
\end{tabular}

When the occurrence of illegal fishing activities were expressed in per hectare basis, Victoria, Sorabora and Ulhitiya reservoirs recorded 0.05, 0.19, 0.06 incidences, respectively. Chi-square test showed that the distribution patterns of various fishing gear usage were not significantly different among the three reservoirs $(P>0.05)$ indicating that the issues to be addressed are generally similar among the reservoirs.

\section{Level of education}

Chi square analysis showed that the three reservoirs were significantly $(P<0.05)$ different with respect to distribution of education level of fishers. A majority of fishers in Victoria and Sorabora reservoirs have received no formal education at all or education only up to primary level, while in Ulhitiya reservoir majority of the fishermen had secondary education which was a positive aspect with respect to human resources involved in fishing (Table 2). The education level of fishers was significantly $(P<0.05)$ associated with illegal fishing activities in Sorabora and Ulhitiya reservoirs. Linear logistic model analysis performed treating education factor as having two levels (Uneducated $=$ no formal education and Educated $=$ primary and secondary levels) showed that tendency for involving in illegal fishing by uneducated fishers was about 6 times and 14 times greater than that of educated fishermen in Sorabora and Ulhitiya reservoirs, respectively (Table 3). 


\title{
Level of engagement in fishing
}

Sorabora fishing community recorded significantly higher $(P<0.05)$ number of full-time fishers than the other two reservoirs. The analysis conducted to determine whether there is an association between level of engagement in fishing and involvement in illegal fishing activities in the three reservoirs (Table 4) showed that only in Ulhitiya part-time fishers were significantly more involved in illegal fishing than full-time fishers $(P<0.05)$, and the estimates of linear logistic model (Table 3 ) showed that the tendency for illegal fishing by part-time fishers was about 4 times greater than that of full-time fishers. It was found that unlike full-time fishers, part-time fishers have other sources of income and have lesser dependency and commitment towards the sustainability of aquatic resource and to fisheries society. Dematawewa et al. (2008) showed that engagement of part-time fishers in fishing, agricultural or any other activity tend to depend on the rainfall and other weather conditions.

Table 2. Engagement in illegal fishing activities (as a percentage) according to the education level of fishermen in three reservoirs

\begin{tabular}{lcccc}
\hline & & \multicolumn{3}{c}{ Education level } \\
\cline { 3 - 5 } Reservoir & Illegal fishing & None & Primary & Secondary \\
\hline \multirow{2}{*}{ Victoria } & Yes & 28.57 & 22.34 & 6.45 \\
\multirow{2}{*}{ Sorabora } & No & 71.43 & 77.66 & 93.55 \\
& Yes & 60.00 & 17.86 & 19.23 \\
Ulhitiya & No & 40.00 & 82.14 & 80.77 \\
& Yes & 77.78 & 13.95 & 25.42 \\
& No & 22.22 & 86.05 & 74.58 \\
\hline
\end{tabular}

\begin{abstract}
Alcohol usage
Frequent consumption of alcohol in any community could lead to management issues and loss of take home salary, particularly in poor communities. When the frequencies of alcohol consumption among fishers were considered, communities in Victoria and Sorabora tanks were having significantly higher $(P<0.05)$ frequency of alcohol consumers. Table 5 shows the alcohol consumption pattern of different groups of fishers in the three reservoirs. Chisquare test revealed that alcohol consumption was significantly associated with those engaged in illegal fishing $(P<0.05)$ across the three reservoirs (Table 5). Particularly in Victoria reservoir, none of the teetotalers engaged in any kind of illegal fishing activities. In contrast, those who consume alcohol daily were the ones who are mostly involved in illegal fishing activities. For linear logistic model analysis, fishermen were divided into two groups as regular consumers (occasional and daily consumers) and others, where the odds ratios for Sorabora and Ulhitiya were 5.2 and 4.55, respectively (Table 3). The results indicate that regular consumers were about 5 times more prone to engage in illegal fishing activities than others in those reservoirs. The factors such as smoking, habit of saving, income, loans obtained, subsidies received for nets and boats were not significantly associated with illegal fishing in all three reservoirs $(P>0.05)$.
\end{abstract}

\section{Holding positions in the fisheries societies}

Majority of the members of the fisheries societies had never held a position in the society in all three reservoirs. This indicates that there was always only a certain percentage of 
members (20-30\%) willing to take up responsible positions in the fisheries society. Chi square analysis showed that the three reservoirs were not different with respect to this tendency $(P>0.05)$.

Table 3. Estimates of linear logistic model analysis for tendency for illegal fishing in the three reservoirs

\begin{tabular}{|c|c|c|c|c|c|c|c|}
\hline \multirow[t]{2}{*}{ Tank } & \multirow[t]{2}{*}{ Factor } & \multirow[t]{2}{*}{ Levels } & \multirow[t]{2}{*}{ Odds } & \multirow[t]{2}{*}{$\begin{array}{l}\text { Odds } \\
\text { ratio }\end{array}$} & \multirow{2}{*}{$\begin{array}{l}\text { Log } \\
\text { odds } \\
\text { ratio }\end{array}$} & \multicolumn{2}{|c|}{$\begin{array}{c}\text { Confidence interval for } \\
\text { odds ratio }\end{array}$} \\
\hline & & & & & & Minimum & Maximum \\
\hline \multirow{6}{*}{ Victoria } & \multirow{2}{*}{$\begin{array}{l}\text { Alcohol } \\
\text { consumption }\end{array}$} & Regular & 4.30 & \multirow{2}{*}{1.07} & \multirow{2}{*}{0.07} & \multirow{2}{*}{0.28} & \multirow{2}{*}{4.06} \\
\hline & & Not & 4.01 & & & & \\
\hline & \multirow{2}{*}{$\begin{array}{l}\text { Organization } \\
\text { position }\end{array}$} & Not held & 13.59 & \multirow{2}{*}{4.57} & \multirow{2}{*}{1.52} & \multirow{2}{*}{1.20} & \multirow{2}{*}{17.34} \\
\hline & & Held/holding & 2.97 & & & & \\
\hline & \multirow{2}{*}{$\begin{array}{l}\text { Participation in } \\
\text { raids }\end{array}$} & No & 11.94 & \multirow{2}{*}{3.70} & \multirow{2}{*}{1.31} & \multirow{2}{*}{1.04} & \multirow{2}{*}{13.15} \\
\hline & & Participated & 3.22 & & & & \\
\hline \multirow{13}{*}{ Sorabora } & \multirow{2}{*}{$\begin{array}{l}\text { Alcohol } \\
\text { consumption }\end{array}$} & Regular & 4.75 & \multirow{2}{*}{5.20} & \multirow{2}{*}{1.65} & \multirow{2}{*}{1.94} & \multirow{2}{*}{13.94} \\
\hline & & No & 0.91 & & & & \\
\hline & Organizing is & No & 4.30 & & & & \\
\hline & useful & Yes & 1.39 & 3.09 & 1.13 & 1.20 & 7.93 \\
\hline & Comply with & No & 5.20 & 28,50 & 3.35 & 1110 & 73.05 \\
\hline & regulations & Yes & 0.18 & 28.50 & 3.35 & 11.10 & 13.05 \\
\hline & Education level & Primary/Sec & 4.48 & 668 & 190 & 260 & 1713 \\
\hline & Latication ic ver & None & 0.67 & 0.08 & 1.90 & 2.00 & 11.10 \\
\hline & & None & 9.49 & & & & \\
\hline & Training & Obtained & 1.31 & 7.24 & 1.98 & 3.10 & 16.88 \\
\hline & & Yes & 0.27 & & & & \\
\hline & Comply with & No & 0.31 & & & & \\
\hline & regulations & Yes & 0.23 & & & & 0.4 .4 \\
\hline & Alcohol & Regular & 4.09 & & & & 1281 \\
\hline & consumption & Not & 0.90 & 4.55 & 1.51 & 1.62 & 12.81 \\
\hline & Fducation leyel & Primary/Sec & 3.86 & 13.46 & 26 & 477 & 3707 \\
\hline & Eutcationit Iever & Non & 0.28 & 10.40 & 2.0 & 4.11 & 31.92 \\
\hline & Fisheries & Not & 5.10 & 1102 & 24 & 205 & 4117 \\
\hline & License & Obtained & 0.46 & 11.02 & 2.4 & 2.95 & 41.17 \\
\hline Ulhitiya & Fishino level & Part time & 5.15 & 434 & 147 & 116 & 1624 \\
\hline & Fisming Ievel & Fulltime & 1.18 & 4.34 & $1.4 /$ & 1.10 & 10.24 \\
\hline & Organizing is & No & 0.66 & 1694 & 283 & 4.30 & 6663 \\
\hline & useful/Willing & Yes & 0.27 & & & & 00.05 \\
\hline & Comply with & No & 0.31 & 2287 & 313 & 612 & 8543 \\
\hline & regulations & Yes & 0.23 & 22.81 & 3.15 & 0.12 & 83.43 \\
\hline
\end{tabular}

The association between tendency to take up positions in the fisheries society and illegal fishing was considered, it was revealed that holding an official position in the fisheries society had significantly lowered tendency for illegal fishing $(P<0.05)$ only in Victoria reservoir (Table 6). According to linear logistic model, the possibility of involving in illegal fishing by a fisher who never held a position in the fisheries society was 4 times greater than those either held or holding positions currently in Victoria reservoir (Table 3). In the other two reservoirs, even certain office bearers have failed to understand the commitments towards their aquatic resource. 
Table 4. Engagement in illegal fishing activities (as a percentage) according to the fishing level of fishermen in the three reservoirs

\begin{tabular}{cccc}
\hline \multirow{2}{*}{ Reservoir } & \multirow{2}{*}{ Illegal fishing } & \multicolumn{2}{c}{ Level of fishing } \\
\cline { 2 - 4 } & & Fulltime & Part time \\
\hline \multirow{2}{*}{ Victoria } & Yes & 17.28 & 21.57 \\
& No & 82.72 & 78.43 \\
\cline { 2 - 4 } Sorabora & Yes & 23.30 & 22.73 \\
& No & 76.70 & 77.27 \\
\cline { 2 - 4 } Ulhitiya & Yes & 16.22 & 45.71 \\
& No & 83.78 & 54.29 \\
\hline
\end{tabular}

However, a significant association $(P<0.05)$ between participation in raids and less engagement in illegal fishing was found only in Victoria reservoir (Table 7). The tendency for illegal fishing by fishers who did not participate in raids was 3.7 times greater than that of fishers who participated (Table 3). These results indicate that a certain number of fishers still engage in certain type of illegal activities even while participating in the raids at least occasionally in the other two reservoirs. This seems to be an issue to be addressed as to why those who help the government officers were still engaged in illegal activities.

Table 5. Engagement in illegal fishing activities (as a percentage) according to frequency of alcohol consumption of fishermen in the three reservoirs

\begin{tabular}{cccccc}
\hline \multirow{2}{*}{ Reservoir } & Illegal & \multicolumn{4}{c}{ Frequency of alcohol usage } \\
\cline { 3 - 6 } & fishing & Teetotalers & $\begin{array}{c}\text { Rarely } \\
\text { taken }\end{array}$ & Occasional & Daily \\
\hline Victoria & Yes & 0.00 & 18.18 & 26.09 & 20.00 \\
& No & 100.00 & 81.82 & 73.91 & 80.00 \\
Sorabora & Yes & 13.33 & 9.52 & 20.59 & 52.38 \\
& No & 86.67 & 90.48 & 79.41 & 47.62 \\
& Yes & 17.95 & 12.50 & 24.32 & 52.63 \\
& No & 82.05 & 87.50 & 75.68 & 47.37 \\
\hline
\end{tabular}

\section{Licensing and registration}

Obtaining license for fishing should be practised annually, and each fisherman is expected to renew their licence annualy, else fishing would be considered as an illegal activity. It was alarming to notice that none of the fishermen have obtained fishing license in Sorabora reservoir during the period from 2014 to 2015 as the responsible government officials were unable to isssue management license during that period. Chi square analysis showed that the differences in number of fishers obtaining license were significant $(P<0.05)$ among reservoirs. However, obtaining a valid license for fishing and legal engagement in fishing was significant only in Ulhitiya reservoir $(P<0.05)$ where it was revealed that fishers who did not obtain management licenses involved in illegal fishing was 11 times more than those who obtained licenses (Table 3). These findings revealed that licensing has not contributed much to reduction of illegal activities in the other two reservoirs. Thus, the fishers seem to obtain the fisheries management licenses only for their security and not to refrain from illegal fishing. 
Table 6. Percentage engagement in illegal fishing activities according to the involvement in activities of fisheries society

\begin{tabular}{ccccc}
\hline \multirow{2}{*}{ Reservoir } & Engaged in & \multicolumn{3}{c}{ Engagement in fisheries Society } \\
\cline { 3 - 5 } & illegal fishing & Held position & Holding position & Member \\
\hline \multirow{2}{*}{ Victoria } & Yes & 15.79 & 0.00 & 25.00 \\
\multirow{2}{*}{ Sorabora } & No & 84.21 & 100.00 & 75.00 \\
& Yes & 15.38 & 10.00 & 27.17 \\
\multirow{2}{*}{ Ulhitiya } & No & 84.62 & 90.00 & 72.83 \\
& Yes & 10.53 & 42.86 & 25.64 \\
& No & 89.47 & 57.14 & 74.36 \\
\hline
\end{tabular}

\section{Training and awareness programs}

The level of participation of fishers in training and awareness programs was significantly different among reservoirs $(P<0.05)$. However, the Chi square analysis conducted within reservoirs has shown that the association between attending training and awareness programs and engage in illegal fishing activities was significant $(P<0.05)$ only in Sorabora reservoir (Table 8). According to the linear logistic model estimates, tendency of fishers who attended training and awareness programs to engage in illegal fishing in Sorabora reservoir was about 7 times lower than those who did not attend the programs (Table 3). Thus, the effectiveness of training programs on illegal fishing activities in the other reservoirs is questionable.

Table 7. Percentage engagement in illegal fishing activities of fishers with respect to their participation in raids

\begin{tabular}{cccc}
\hline \multirow{2}{*}{ Reservoir } & Illegal Fishing & \multicolumn{2}{c}{ Participation in Raids } \\
\cline { 3 - 4 } & & Participated & Not Participated \\
\hline Victoria & Yes & 7.69 & 23.66 \\
& No & 92.31 & 76.34 \\
Sorabora & Yes & 12.00 & 26.00 \\
& No & 88.00 & 74.00 \\
Ulhitiya & Yes & 14.29 & 27.78 \\
& No & 85.71 & 72.22 \\
\hline
\end{tabular}

\section{Attitudes of the fishers}

Views of fishermen towards Fisheries Societies were assessed on three different aspects. Usefulness of organizing of communities to improve the living standards of fishermen was one of the aspects considered. Over 80 percent of the fishermen in all three reservoirs believed that organizing of communities would help to improve their living standards. Sultana and Thompson (2007) showed that in general, participants perceive a considerable increase in their role in fisheries management decision making through the community organizations. There was a significant association $(P<0.05)$ between this opinion and involvement in illegal fishing activities in all three reservoirs indicating that fishers who believed in getting organized were less likely to get involved in illegal fishing activities (Table 9). 
Table 8. Percentage engagement in illegal fishing activities by fishermen with respect to their participation at the training and awareness programs

\begin{tabular}{cccc}
\hline \multirow{2}{*}{ Reservoir } & Engaged in & \multicolumn{2}{c}{ Training and awareness programs } \\
\cline { 3 - 4 } & illegal fishing & Participated & Not participated \\
\hline \multirow{2}{*}{ Victoria } & Yes & 14.75 & 22.54 \\
\multirow{2}{*}{ Sorabora } & No & 85.25 & 77.46 \\
& Yes & 9.46 & 43.14 \\
\multirow{2}{*}{ Ulhitiya } & No & 90.54 & 56.86 \\
& Yes & 13.64 & 28.09 \\
& No & 86.36 & 71.91 \\
\hline
\end{tabular}

Linear logistic analysis revealed that fishermen in Sorabora and Ulhitiya tanks, who did not believe in getting organized into societies tended to get involved in illegal fishing 3 and 20 times more than the others, respectively (Table 3). The other aspect considered was whether the fishermen themselves were willing to be organized into their own fisheries society. Those who believed in the usefulness of a fisheries society were generally willing to get organized. In Victoria and Ulhitiya reservoirs, fishermen who believed in effectiveness of strengthening their own fisheries societies were shown to be less likely to get involved in illegal activities $(P<0.05)$. In Ulhitiya, those who believed in strengthening of their own society were about 20 times less likely to be engaged in illegal fishing activities (Table 3).

Table 9. Engagement in illegal fishing activities according to response on opinions of fishermen in the three reservoirs

\begin{tabular}{cccccccc}
\hline Reservoir & $\begin{array}{c}\text { Illegal } \\
\text { fishing }\end{array}$ & \multicolumn{2}{c}{$\begin{array}{c}\text { Organizing is } \\
\text { considered useful }\end{array}$} & \multicolumn{2}{c}{$\begin{array}{c}\text { Willing to organize } \\
\text { into own society }\end{array}$} & \multicolumn{2}{c}{$\begin{array}{c}\text { Comply with } \\
\text { regulations }\end{array}$} \\
\cline { 2 - 8 } & & Yes & No & Yes & No & Yes & No \\
\hline Victoria & Yes & 15.08 & 100.00 & 15.08 & 100.00 & 17.05 & 100.00 \\
& No & 84.92 & 0.00 & 84.92 & 0.00 & 82.95 & 0.00 \\
Sorabora & Yes & 81.19 & 56.52 & 20.95 & 35.00 & 16.07 & 84.62 \\
& No & 18.81 & 43.48 & 79.05 & 65.00 & 83.93 & 15.38 \\
& Yes & 17.53 & 78.57 & 17.53 & 78.53 & 15.79 & 81.25 \\
& No & 82.47 & 21.43 & 82.47 & 21.47 & 84.21 & 18.75 \\
\hline
\end{tabular}

The third aspect investigated was whether the fishermen agree to comply with fisheries regulations. The percentage of fishermen who were not willing to comply with the fisheries regulations was less than 20 percent in the three reservoirs, but the exact percentages were significantly different from one another $(P<0.05)$. Chi square analysis proved that noncompliance with fisheries regulations was significantly associated $(P<0.05)$ with illegal fishing in all these reservoirs (Table 9). According to the linear logistic model analysis, the fishermen in Sorabora and Ulhitiya reservoirs who disagreed to comply with regulations had the tendency to violate fisheries regulations 28.5 and 22.9 times more than the group which is willing to comply, respectively (Table 9).

When the odds ratio between two levels of a risk factor is equal to one, implies that there is no difference between the relative risks associated with the two levels. Similarly, if the confidence interval of the odds ratio does not include 1.0, that means the risks associated with the two levels are significantly different. Only the risk factors that show a significant influence on illegal fishing were reported in Table 3. None of the interactions between the 
risk factors included in the linear logistic model were found to be significant with respect to tendency for illegal fishing $(P<0.05)$.

\section{Improvements in management}

The management procedures existed in the three reservoirs before January 2014 were based on Community Based Management method where the government played a major role in managing the aquatic resource, while only the fishers and other beneficiaries were excluded in decision making process. However, during the study period, management method had been transforming gradually into co-management with more involvement of all stakeholder's in the resource management as shown by Fernando et al. (2015). Kulathilake et al. (2010) stressed that certain critical issues have to be resolved for effective co-management such as amending the Fisheries and Aquatic Resources Act by providing legal framework for comanagement, and administrative reorganization of the respective government agencies that have fisheries regulatory functions. Since then some improvements have been incorporated into the Act in bringing it to the present form (Fisheries and Aquatic Resources (Amendment) Act, No. 11 of 2017). Establishing an effective co-management process is not only a matter of building institutions but a matter of building trust between the parties (Plummer and FitzGib-bon, 2007) and also providing resource users a certain level of autonomy (Jayasundara and Edirisinghe, 2005). Findings of this study revealed that an effective co-management strategy should be derived with the contribution of all stakeholders while emphasizing the importance of strengthening the fisheries societies.

\section{CONCLUSIONS}

The findings of the present study clearly indicate the relative importance of certain socioeconomic factors of fishing community and effectiveness of present management steps on mitigating illegal fishing activities. The issues and effectiveness of the management steps seem to vary among the reservoirs considered indicating that reservoir specific comanagement strategies are required to be developed to achieve the fullest benefits and sustainability of the reservoir management.

\section{REFERENCES}

Anonymous, (2013). Fisheries sector development strategy 2010-2013. Ministry of Fisheries and Aquatic Resources Development. Maligawatta, Colombo 10.

Anonymous, (2016). Fisheries Statistics Report-2016. Planning and Monitoring Unit, Ministry of Fisheries and Aquatic Resources, Colombo, Sri Lanka.

Amarasinghe, U.S. and De Silva, S.S. (1999). Sri Lankan reservoir fishery: a case for introduction of a co-management strategy. Fisheries Management and Ecology. 1999(6), 387-399.

Dematawewa, C.M.B., Wickremasinghe, E.S. and Edirisinghe, U. (2008). Some effects of seasonal hydro-climatic factors on catchability of fish in minor-perennial Sorabora reservoir, Sri Lanka. Sri Lanka Journal of Animal Production. 4(1), 9-24. 
De Silva, S.S. (1988). Reservoirs of Sri Lanka and their fisheries. FAO Fisheries Technical Paper. (298), 128pp.

Etiegni, C.A., Ostrovskaya, E., Leentvaar, J. and Eizinga, F. (2011). Mitigation of illegal fishing activities: enhancing compliance with fisheries regulation in Lake Victoria (Kenya). Regional Environmental Change.11(2), 323-334.

Fernando, W.M.J.R., Chandrasoma, J., Pushpalatha, K.B.C. and Kulathilaka, M. (2015). Comanagement of the fishery of Senanayake Samudra, a large perennial reservoir in Sri Lanka. Sri Lanka Journal of Aquatic Science. 20(2), 9-18.

Jayasundara, A.S. and Edirisinghe, U. (2005). Identification of the co-management strategies for the management of the fishery in Ibbankatuwa reservoir, Dambulla. Proceedings of $13^{\text {th }}$ Annual Students Research Session, Department of Animal Science, Faculty of Agriculture, University of Peradeniya, Peradeniya.

Kulathilake, M., Liyanage, H.S.W.A., Fernando, W.M.J.R., Chandrasoma, J. and Van der Knaap, M. (2010). Development of co-management in the inland fisheries in Sri Lanka: Case studies of Senanayake Samudra and Mahavilachchiya reservoirs. Aquatic Ecosystem Health and Management. 13(3), 294-300.

Plummer, R. and FitzGib-bon. (2007). A resilience-based framework for evaluating adaptive co-management: Linking ecology, economics and society in a complex world. Ecological Economics. 61(1), 62-74.

Sultana, P. and Thompson, P.M. (2007). Community based fisheries management and fisher livelihoods: Bangladesh case studies. Human Ecology. 35, 527-546.

Sumaila, U.R., Alder, J. and Keith, H. (2006). Global scope and economics of illegal fishing. Marine Policy. 30(6), 696-703.

Wickremasinghe, E.S., Dematawewa, C.M.B. and Edirisinghe, U. (2009). Illegal fishing practices: a case study in Sorabora reservoir, Sri Lanka. Sri Lanka Journal of Animal Production. 5(1), 3-27. 